\title{
EMANCIPAÇÃO E EDUCAÇÃO: UTOPIAS DO SÉCULO XVI E PROPOSTAS EDUCACIONAIS “INOVADORAS" DA ATUALIDADE.
}

\author{
EMANCIPATION AND EDUCATION: UTOPIAS OF THE SIXTEENTH CENTURY AND \\ "INNOVATIVE" EDUCATIONAL PROPOSALS IN THE CURRENT DAYS
}

Vilson Aparecido da Mata*

\section{RESUMO}

Este trabalho pretende analisar as relações existentes entre o discurso atual sobre a emancipação através da Educação, enunciado pelas propostas educacionais ditas inovadoras, e as obras publicadas no século XVI, como Utopia, de Thomas More, onde a emancipação estava condicionada a uma transformação social profunda. A emancipação, como categoria, foi abordada por Marx em suas obras de juventude, ora como categoria de análise da emancipação religiosa (A Questão Judaica), ora como categoria condicionada pela alienação (Manuscritos Econômico-Filosóficos). Uma Utopia, em determinado momento histórico, aparece como discurso de fronteiras sempre móveis, sempre alguns passos à frente da realidade objetiva. Ela também se constitui como obra crítica ao existente em sua época. A partir desta constatação, propõe-se a análise do discurso emancipatório presente nas propostas educacionais ditas -inovadorasll na atualidade, que atribuem ao poder presente na individualidade, na subjetividade e no protagonismo do aluno a emancipação do homem, desprezando ou desconsiderando a complexidade do contexto histórico social mais amplo. Com esta proposta, pretende-se discutir limites e potencialidades das propostas educacionais ditas -inovadorasll.

PALAVRAS-CHAVE: Emancipação - Educação - Utopia

\begin{abstract}
This work aims to analyse the existing relations between the current speech about the emancipation through Education, announced by the stated innovative educational proposals, and the titles published in the sixteenth century, like Utopia, by Thomas More, in which the emancipation was conditioned to a profound social change. The emancipation, as a category, was broached by Marx in the titles he wrote when young, either as a category of analysis of the religious emancipation (The Jewish Question), or as a category conditioned by the alienation (Philosophical-Economical Manuscripts). An Utopia, in a certain historical moment, which arises like a speech of movable bounds, which are always a step ahead the objective reality. It is also constituted as a title which was critical to what existed at its period. From this finding, the analysis of the emancipation speech, present at the stated -innovativell educational proposals in the current days is proposed, which attributes to the
\end{abstract}


power present in the individuality, in the subjectivity, in the leading figure of the pupil and in the emancipation of man, despising or disregarding the complexity of a wider social historical context. It is intended, with this proposal, to discuss the limits and potentiality of the stated

-innovativell educational proposals.

KEYWORDS: Emancipation - Education — Utopia.

\section{INTRODUÇÃO}

"Deixar de ver o outro como uma ameaça e passar a vê-lo como uma promessa".

Eduardo Galeano

Em diferentes momentos da história humana, o sonho por uma sociedade melhor do que a existente foi acalentado como possibilidade de superação de condições insatisfatórias do presente. Ora na forma de protestos diretos em direção a uma revolução social; ora na forma de obras artísticas (no caso deste texto, literárias), o descontentamento com a sociedade existente encontrou diferentes canais de expressão. Uma característica presente nos clássicos da literatura mundial é exatamente expressar as contradições presentes em seu tempo e, por isso mesmo, tornam-se importantes instrumentos de pesquisa para a melhor compreensão da própria realidade. Ao retratar um homem em particular, historicamente localizado e fictício, o autor da obra literária expressa o espírito do seu tempo (Zeitgeist), ao qual o personagem não pode deixar de corresponder e do qual não pode diferenciar-se. Concordando ou divergindo do movimento e dos acontecimentos de seu tempo, tanto personagem quanto obra literária expressam tendências, pressupostos, concepções e valores sociais daquele tempo e que se estendem para os dias do futuro. É neste sentido que se pode identificar o valor inestimável da obra literária para a educação.

O estudo dos clássicos contribui para o entendimento das condições existentes em uma determinada organização social, como, por exemplo, a presença de elementos que indicam a repetição e reprodução daquilo que efetiva e disciplina na direção da manutenção de um determinado estado de coisas. Buscar os elementos que fundamentam a formação do ser humano em tempos históricos passados através de clássicos da literatura mobiliza a compreensão do movimento histórico que gestou as concepções, ideais e ações presentes na atualidade.

Nesse sentido, os clássicos são obras educacionais, uma vez que ensinam aos 
homens do futuro sobre os valores, princípios, sociabilidade, conhecimentos e anseios de sua época. Pelo caráter educacional dos clássicos torna-se possível encontrar as ideias que os homens produzem sobre si próprios, sobre seu tempo, sobre sua condição humana: -As ideias que esse homem constrói sobre si próprio e as formas que desenvolve para educar e formar as gerações mais jovens dão indicativos das necessidades que se impunham em períodos específicos desse caminhar histórico do ser humanoll ${ }^{1}$. Quando, porém, os processos que formam as novas gerações passam a ser entendidos como independentes do movimento mais amplo da sociedade, desconsiderando as condições históricas que a constituem, identificam-se indícios de esgotamento da própria estrutura social, uma vez que o processo de formação das gerações mais jovens é inseparável de um projeto social historicamente construído.

$\mathrm{Na}$ crítica e na insatisfação com o estado de coisas existentes surgem manifestações que apontam caminhos diferentes. No Renascimento, Thomas More escreveu Utopia, em 1516². Imaginando uma sociedade mais igualitária e feliz, criticava e denunciava as bem desnudas desigualdades e contradições que se apresentavam na sociedade capitalista em seu nascedouro. Tamanha a importância dessa obra que outras a ela se seguiram, tornando em gênero literário os textos escritos neste estilo ${ }^{3}$. Em Utopia, há clareza na compreensão de que a superação do feudalismo era desejável para a humanidade, porém, o modelo do trabalho assalariado que se constituía não bastava para livrar o homem das mazelas, desigualdades e miséria.

Mas é apenas no século XIX, com Karl Marx, que a superação das mazelas sociais e da crueza da expropriação e desumanização representada pelo trabalho assalariado se apresenta como emancipação humana ${ }^{4}$. Para o autor alemão, o desenvolvimento do capitalismo foi essencial para que as forças produtivas ganhassem universalidade, mas 0 capitalismo não seria capaz de promover emancipação de todos os seres humanos. Inevitavelmente, as forças produtivas do capital entrariam em contradição com o desenvolvimento humano e isso indicaria transformações.

A educação, então, é pensada aqui como uma das esferas sociais. Em seu duplo caráter, ao mesmo tempo em que reforça a ordem social do capital, contém em si os elementos de superação da emancipação política em direção à emancipação humana. A questão que se pretende expor neste artigo é que, concebida como esfera independente do movimento social e histórico mais amplo, a educação não pode assumir seu papel na emancipação 
humana, pois mantém a perspectiva de conservação da ordem social atual, efetivando um discurso de liberdade encarcerada nas relações sociais de exploração e de alienação.

A primeira parte do texto abordará a utopia como gênero literário que apresenta projeto de sociedade melhor, a partir da obra fundante desse gênero, escrita por Thomas More em 1516: na impossibilidade de emancipação humana a partir da transformação da sociedade existente, esta emancipação só se realiza numa sociedade em que o trabalho coletivo e a abolição da propriedade privada dos meios de produção fossem realizados; a segunda parte do texto trata da emancipação em seu duplo caráter: emancipação política e emancipação humana, procurando demonstrar a diferença existente entre uma concepção utópica de superação da sociedade capitalista e a necessidade material desta superação; ao final, a análise se concentra na problematização da perspectiva educacional como promotora da liberdade individual, independente do movimento mais amplo da sociedade, tida como emancipadora, mas na realidade, constituindo-se como reforçadora da própria ordem social que pretende criticar e superar.

\section{UTOPIA E FORMAÇÃO HUMANA: A EDUCAÇÃO PELO TRABALHO COLETIVO}

O século XVI marca um momento de intensas transformações no mundo ocidental: por um lado, a nova forma de organização do trabalho se impunha brandindo os princípios da liberdade. O capitalismo amanhecente desenvolvia-se no seio da tendência liberal. Por outro lado, a agonizante ordem social feudal, em seus estertores, ainda acumulava alguma força para sobreviver diante das inevitáveis transformações. Neste momento da história, em que a devassa herança do passado se tornava evidente e a ainda nebulosa esperança no futuro não se vislumbrava, configurava-se uma situação que sugeria grandes transformações:

Há momentos em que as alternativas sócio-históricas estão relativamente em aberto. Nestes momentos, é possível vislumbrar, como que por um buraco de fechadura, as características objetivas da ordem social emergente. Estes são momentos de crise histórica que proporcionam alguma abertura e criam um vácuo ideológico que favorece o aparecimento de -ideologias utópicasll. (MÉSZÁROS, 2007, p. 40).

Naquele momento histórico de transformações e crise, o modelo de uma sociedade distante, completamente diferente da existente na Europa expunha os desequilíbrios, 
contradições e injustiças presentes no capitalismo nascente. A confiança na ciência e no desenvolvimento tecnológico de Utopia era a garantia de emancipação para seu povo. De certo modo, Utopia foi uma obra que apresentou um projeto de sociedade melhor, diferente e mais justa.

Uma utopia nasce das contradições entre o desenvolvimento das forças produtivas e as mazelas e desequilíbrios causados por essas mesmas forças. Nutrindo-se de sua realidade histórica, manifesta a insatisfação com a contradição de uma ordem social injusta que impossibilita a emancipação humana. Sem a contradição, sem o movimento de transformação, sem o eterno construir e desconstruir das sociedades, projetos sonhadores são impossíveis. E o movimento histórico do Renascimento era o do progresso: social, científico, enfim, da Razão.

O progresso foi o lema de uma miríade de propostas e ideias naquele momento, foi o dístico de toda utopia. O progresso da razão deu corpo ao questionamento do existente, opondo o desenvolvimento real e as possibilidades que uma sociedade qualitativamente diferente poderia oferecer. Embora os estertores da ordem feudal só tenham encontrado seu apogeu três séculos mais tarde, já há, claramente, o clamor pela liberdade. A propriedade feudal ainda é a base sobre a qual se levantam todas as instituições, porém, algumas vozes dissonantes apontam para uma possibilidade completamente nova: o homem livre.

É no século XVI que Leonardo da Vinci pinta a Mona Lisa; que Martinho Lutero inicia a Reforma; que Francisco Pizarro lidera a conquista espanhola do Novo Mundo, pouco antes -descobertoll pelos portugueses; que Camões compõe Os Lusíadas e que Shakespeare escreve, entre outras, Hamlet. No campo do pensamento, Elogio da Loucura, de Erasmo de Rotterdam ganha vida no século XVI, bem como as Meditações, de Descartes, e também Ensaio acerca do Entendimento Humano, de John Locke. O século XVI é o apogeu do Renascimento, momento histórico em que as conquistas do mundo antigo (principalmente grego e romano) são retomadas, tanto no campo da filosofia quanto no campo da política, da poesia, da arte (escultura e pintura). A retomada de pensadores gregos, como Platão e Aristóteles impõe ao mundo ocidental a reavaliação dos ideais tidos, pelo pensamento medieval, como criação atemporal.

Tal movimento dá corpo ao entendimento de que o homem não é, necessariamente, refém de seu destino, mas livre para construir sua própria realidade a partir das condições dadas. 
A defesa dessas ideias, bem como que o planeta Terra não é o centro do universo e se move em torno do Sol levou à fogueira da inquisição, em 1600, o padre e filósofo Giordano Bruno e obrigou Galileu Galilei a retratar-se diante de um tribunal da inquisição. A compreensão de que o homem é livre para aplicar suas forças e capacidades como melhor Ihe aprouver continuou inabalável, pavimentando o caminho para a concepção de trabalho livre e o questionamento sobre a propriedade feudal.

Esse é o cenário no qual vive Thomas More, homem de estado, diplomata, escritor, advogado e beatificado por ter morrido na prisão em defesa da fé cristã na Inglaterra. $O$ autor do texto analisado nesta parte do artigo viveu e entendeu como poucos o seu tempo, constatando as transformações que então se processavam, foi capaz de entender que aquilo que parecia a libertação do homem poderia vir a se constituir em seu cativeiro. Por um lado, o trabalho livre, não servil, liberta das amarras feudais, mas, para aqueles que nada possuem, ele aprisiona no assalariamento.

Os ricos diminuem cada dia alguma coisa no salário dos pobres, não só por meio de manobras fraudulentas, mas ainda decretando leis para tal fim. Recompensar tão mal aqueles que mais merecem da república, parece-nos, à primeira vista uma evidente injustiça; mas os ricos fazem desta monstruosidade um direito, sancionando-o em leis. (MORE, 2007, p. 132).

A partir da constatação das desigualdades existentes, More projeta, na imaginária ilha de Utopia, o gosto pelo trabalho, livre e emancipado, que representa ruptura com o trabalho servil medieval, e também com o trabalho explorado do operário assalariado. Ambos parecem, a More, insatisfatórios e incapazes de levar a humanidade à autorrealização. $A$ razão e o domínio da ciência libertariam o homem da superstição e da ignorância, elevando seus horizontes sociais e promovendo a convivência coletiva e harmônica, sem acumulação e propriedade privada, sem o uso arbitrário do poder.

É no trabalho que More vê todo potencial de emancipação em Utopia: -Não se deve crer que os utopianos se atrelam ao trabalho como bestas de carga desde a madrugada até a noite. Esta vida, embrutecedora para o espírito e para o corpo, seria pior que a tortura e a escravidão. E, no entanto, tal é, em outra qualquer parte, a triste sorte do operário!ll. (MORE, 2007, p. 68).

A compreensão de que o trabalho, nos moldes do capitalismo nascente, 
embrutece e aliena o homem, denuncia algo que só será profundamente analisado por Marx e Engels no século XIX, quando o trabalho capitalista já havia encontrado pleno desenvolvimento, esta questão será retomada no próximo tópico.

O gosto pelo trabalho em Utopia não serve apenas para a produção das riquezas sociais equitativamente divididas na ilha dos sonhos, mas é a partir do trabalho que cada habitante expressa sua individualidade, sua subjetividade, na medida em que tudo que produz leva, de certo modo, sua assinatura. Seja o trabalho nos campos arando a terra e criando animais, seja o trabalho intelectual que produz as riquezas do espírito ou ainda o trabalho artesanal, que produz as riquezas culturais, é o trabalho o instrumento mais importante para a formação do homem emancipado e livre, se comparado ao europeu. Mesmo assim, o trabalho não é a atividade sacrificada, dolorosa e embrutecedora que predomina na Europa, ao contrário, o tempo de trabalho é mínimo, seis horas por dia, para que haja tempo para outras atividades que enriqueçam todas as esferas humanas: - [...] as seis horas de trabalho produzem abundantemente para todas as necessidades e comodidades da vida, e ainda um supérfluo bem superior às exigências do consumoll. (MORE, 2007, p.69).

A produtividade do trabalho está relacionada com o fato de que, em Utopia, não há pessoas em idade de trabalhar que não trabalhem, além do mais, as atividades que não sejam verdadeiramente necessárias não são realizadas. Aqui More apresenta uma crítica direta aos desequilíbrios da especulação e da ambição do capitalismo ainda em seu berço:

\begin{abstract}
Porque, neste século de dinheiro, onde o dinheiro é o deus e a medida universal, grande é o número das artes frívolas e vãs que se exercem unicamente a serviço do luxo e do desregramento. [...] Supondo, pois, que se faça trabalhar utilmente aqueles que não produzem senão objetos de luxo e os que nada produzem, embora comam o trabalho e o quinhão de dois bons operários; então, concebereis, sem dificuldade, que disporão de mais tempo do que necessitam para prover às necessidades e mesmo aos prazeres da vida, quero dizer, os que fundam na natureza e na verdade. (MORE, 2007, pp. 6970).
\end{abstract}

O trabalho é essencialmente familiar em Utopia. Valores e deveres, posturas e habilidades necessários ao desenvolvimento de um ofício são despertados nos jovens como processo de inserção no feixe de relações sociais produzidas. O trabalho é o fundamento sobre o qual se elevam todas as relações sociais. Embora, conforme More, os utopianos tenham no trabalho livre o elemento crucial para a coesão da sociedade, -o povo utopiano é espiritual, amável, engenhoso, ama o lazer, é paciente no trabalho, quando o trabalho é necessário; sua paixão favorita é o exercício e o desenvolvimento do espíritoll (MORE, 
2007, p. 95). A convivência social, a curiosidade em relação à natureza, as leis e toda a complexidade da sociedade é despertada e compreendida a partir do trabalho. Para a curiosidade em relação ao mundo e seu funcionamento, há os cursos públicos todas as manhãs, para onde - [...] o povo acorre em massa; e cada um se apega ao ramo de ensino que tem mais relação com sua indústria e seus gostosll. (MORE, 2007, p. 68).

Não há propriedade privada em Utopia, portanto, o trabalho coletivo gera riquezas para toda a comunidade da ilha sonhadora. A competição por maior lucro ou mais riquezas inexiste, bem como o indivíduo egoísta. Todos dispõem de tudo quanto for necessário para a vida confortável. O verdadeiro progresso da humanidade, no texto utópico, não está na competição, mas na razão que, potencialmente, cria o homem socialmente integrado, humanizado nas relações sociais e não embrutecido no assalariamento da sociedade existente.

O fim das instituições sociais da Utopia é de prover antes de tudo às necessidades do consumo público e individual; e deixar a cada um o maior tempo possível para libertar-se da servidão do corpo, cultivar livremente o espírito, desenvolvendo suas faculdades intelectuais pelo estudo das ciências e das letras. É neste desenvolvimento completo que eles põem a verdadeira felicidade. (MORE, 2007, p. 71).

Não dispondo de espaço para um desenvolvimento mais complexo da descrição da obra de Thomas More, cabe concluir que, na ilha de Utopia, o autor inglês projeta os ideais de igualdade, liberdade e elevação humanos ausentes na sociedade europeia de então. A ilha sonhadora, embora exista somente na imaginação de um escritor brilhante, denuncia as promessas não realizadas de liberdade e abundância para todos. Utopia retrata o homem historicamente localizado do Renascimento e, embora fictícia, denuncia os benefícios humanos ausentes na sociedade existente, e, divergindo do movimento histórico de seu tempo, projeta uma sociedade na qual estejam presentes todos os elementos que dão corpo à verdadeira liberdade humana, que não pode ser a liberdade do indivíduo desconectado das relações sócio-históricas, mas antes, a liberdade na comunidade, liberdade conquistada coletivamente, onde o outro homem não se impõe como inimigo, mas como a própria expressão da minha liberdade.

Como o produto inevitável do progresso capitalista é a desigualdade, a ideia de que ele realiza a emancipação humana é falsa. No século XVI, a emancipação das condições desumanas em que a grande massa européia vivia era impossível. O texto utópico leva a 
compreender que nenhum projeto emancipatório baseado somente na reforma do sistema social desigual existente pode ser projeto de emancipação do homem, pois esta é produto da transformação social de totalidade, não pode ser confundida com reformas sociais que levem a mais — progressoll nos moldes capitalistas, este modelo de progresso constitui uma parcialidade apenas.

\section{EMANCIPAÇÃO POLÍTICA E HUMANA: O DUPLO CARÁTER DA EMANCIPAÇÃO}

Na Utopia, o gosto pelo trabalho e o usufruto coletivo e equitativo do seu produto leva a imaginar uma sociedade perfeita. A emancipação conquistada passou, antes de tudo, pela abolição da propriedade privada dos meios de produção e do acúmulo de lucros por uns poucos à custa da exploração de muitos; foi conquistada, portanto, na superação da alienação do trabalho explorado. A universalidade do trabalho produziu, nestes moldes, uma sociedade em que o particular e o social não se encontram em oposição hostil.

Por um lado, Thomas More observa com precisão os limites da embrionária forma societária capitalista e, por outro lado, é apenas no século XIX, a partir das descobertas de Karl Marx, que a diferença entre emancipação humana e emancipação política se tornará clara. Marx analisou uma sociedade capitalista desenvolvida e em pleno processo de universalização. Para Marx, o entendimento a-histórico de que a propriedade privada dos meios de produção seja eterna, natural e independente das relações sociais é um empecilho para a realização da emancipação humana. A conservação da sociedade civil burguesa não efetiva a liberdade porque reduz o humano à parcialidade do individualismo. A liberdade do homem egoísta, parcial, entendido como uma mônada isolada não se baseia na união do homem, mas na sua separação em relação ao seu semelhante, é uma liberdade murada. Evidentemente, se é liberdade parcial, então, não é liberdade, porque a sua limitação faz com que o homem dobre-se sobre si mesmo, não vendo a si como ser genérico, ao contrário, faz da vida genérica, da sociedade, algo exterior, estranho. É a emancipação política.

Para ser verdadeiramente livre, a humanidade não pode permanecer prisioneira da propriedade privada dos meios de produção, pois a estrutura que aprisiona mantém as desigualdades e ostenta os grilhões da não liberdade na forma de Estado político garantidor das relações sociais burguesas: - a necessidade prática, o egoísmo, é o princípio da 
sociedade burguesa, e torna-se visível de forma pura tão logo a sociedade civil extrai completamente de si o Estado políticoll. (MARX, 2005, p.172)

Em sua estrutura, a sociedade civil burguesa não pode efetivar a liberdade humana, uma vez que a contradição entre capital e trabalho; a competição e o egoísmo são óbices à liberdade. A consequência disso é o aprofundamento da miséria, da exploração, da dissolução da consciência da relação vital, necessária, do homem com o mundo natural e com os demais seres humanos.

A unidade entre o particular e o universal expresso em Utopia denuncia a contradição entre a parcialidade do interesse individual e a universalidade das relações sociais alienadas presentes na Europa. Fica evidenciada uma universalidade fictícia: o sujeito egoísta surge como a única essência humana possível. A contradição hostil entre a particularidade e a universalidade faz com que o homem seja entendido como mônada desde os primórdios do capitalismo. A parcialidade põe-se como a própria expressão do sujeito egoísta.

\footnotetext{
Pois a —parcialidadell e a —universalidadell, em sua oposição recíproca, são duas facetas do mesmo estado alienado de coisas. A parcialidade egoísta deve ser elevada à —universalidadell para sua realização: o dinamismo socioeconômico subjacente é ao mesmo tempo -autocentradoll e -dirigido para forall, —nacionalistall e -cosmopolitall, —protecionista-isolacionistall e -imperialistall. É por isso que não pode haver lugar para a universalidade autêntica, mas apenas para a falsa universalização da mais crua parcialidade, justamente como um postulado ilusório, teórico-abstrato, da universalidade como restrição - meramente ideológica - da parcialidade efetiva, predominante na prática. (MĖSZÁROS, 2007, p. 35).
}

A parcialidade elevada à condição de universalidade fictícia acentua a alienação do trabalho. Quando a consciência humana alcança esta compreensão é que se torna possível pensar, como Marx, na transcendência da parcialidade como transcendência prática da alienação, na emancipação. O trabalho alienado não pode produzir emancipação, ele produz somente alienação. Na medida em que o trabalho alienado é universalizado, a alienação torna-se universal. A liberdade fica limitada às migalhas que caem da mesa do trabalho alienado. - A liberdade individual e sua aplicação constituem o fundamento da sociedade burguesa. Sociedade que faz que todo homem encontre em outros homens não a realização de sua liberdade, mas, pelo contrário, a limitação destall. (MARX, 2005, p. 35). A emancipação política não suprime, nem pode suprimir, os princípios e a lógica capitalista. Antes, a emancipação política reforça a cisão do homem em vida pública e vida privada, pressupondo o aprisionamento deste mesmo homem à ordem de propriedade privada real. 
A emancipação política é representada pela desintegração do homem. Sendo parcial e restrita, não alcança a totalidade das relações histórico-sociais presentes na sociedade capitalista, restringindo-se a aspectos isolados, como a educação, por exemplo. Ao não conseguir libertar sequer do aspecto parcial e restrito, a emancipação política devolve exatamente aquilo que pretende suprimir: o egoísmo, o individualismo e a moral burguesa. A emancipação política é construída na própria perspectiva do capital. Não supera a alienação e nutre o antagonismo entre a crença na emancipação e a prática social concretamente alienante. Obter a emancipação política sem obter a emancipação humana é uma meia solução, porque a emancipação política pressupõe uma liberdade parcial, mas também uma sujeição geral. Quando há defesa da emancipação, mas não se questiona profundamente a ordem social que aliena, apenas a intenção moral da emancipação se evidencia. Quando se defende a emancipação dentro dos limites da própria ordem que a aprisiona, revela-se unicamente a exortação moral por uma emancipação cindida, parcial, restrita.

A emancipação humana não se realiza aprisionada à lógica da sociedade da propriedade privada, cujo elemento fundante é a alienação do trabalho que, de antemão, a impede. Emancipação humana realiza-se apenas na negação e na superação da ordem social que a aprisiona. É transformação qualitativa, é mudança no modo como as forças produtivas se organizam. Assim sendo, não pode prescindir da ruptura com a essência do capital: a propriedade privada dos meios de produção e a alienação do trabalho. A emancipação humana não está, portanto, realizada pura e simplesmente no aforismo moral da liberdade nos limites da ordem social vigente. Neste caso, o que há é a expectativa de emancipação política. - - [...] Somente quando o homem tenha reconhecido e organizado suas forces propres como forças sociais e quando, portanto, já não separa de si a força social sob a forma de força política, somente então se processa a emancipação humanall. (MARX, 2005, p. 42).

Para Marx, a emancipação humana representa a transformação profunda da sociedade baseada na contradição entre capital e trabalho. Entretanto, esta não é uma tarefa que se cumprirá —naturalmentell. Ela demanda a ação organizada e consciente dos homens unidos em torno do objetivo maior de superação das contradições presentes sob a ordem social do capital em todas as suas esferas, desde a produção da matéria prima essencial 
até as mais elevadas formas de organização política da cadeia produtiva e o pensamento filosófico, religioso e a arte.

A emancipação humana só pode ter lugar com a anulação, a destruição e a superação da propriedade privada dos meios de produção. É uma tarefa que diz respeito à totalidade da sociedade, mas que não se efetiva a partir do sonho utópico de um mundo melhor apenas, demanda que os homens tomem a história em suas mãos. A constituição da emancipação humana não é uma consequência natural do fim do capitalismo, mas, antes, uma construção histórica dos seres humanos. —Não se trata de investigar, apenas, quem há de emancipar e quem deve ser emancipado. A crítica tem de indagar-se, além disso, outra coisa: de que espécie de emancipação se trata; quais as condições implícitas da emancipação que se postulall. (MARX, 2005, p. 15). É somente a partir da clareza sobre qual é a espécie de emancipação que se postula que se torna possível pensar a educação. Esta é a questão a ser abordada no próximo tópico.

\section{EMANCIPAÇÃO E PROJETO EDUCACIONAL NA ATUALIDADE}

Neste início de século, o abandono de projetos de transformação radical da sociedade, o desencanto com o futuro, a violência e a desesperança, sugerem uma imobilidade que estende ao futuro o aprofundamento do indesejável no presente (VAZQUEZ, 2001). século XXI vê generalizar-se o consumismo e a desvalorização geral da força de trabalho, aprofundando o grau de alienação, obliterando o sonho de uma sociedade diferente da existente, uma vez que apenas o momento presente se coloca como importante: -o futuro fica parecendo o presente com mais opçõesll (JACOBY, 2001, p. 62).

Neste processo, pode-se constatar que há, na educação, um duplo caráter: em primeiro lugar, em sentido mais amplo, a educação é a promotora e a conservadora dos conhecimentos acumulados historicamente e transmitidos de geração em geração. Não é a educação que produz tais conhecimentos, mas é dela a função de garantir que as gerações mais jovens não repitam os mesmos erros das gerações mais antigas, utilizando como ponto de partida suas conquistas para avançar confirmando, negando, reconstruindo e reformando os conhecimentos antigos, bem como descobrindo, a partir daquilo que já está historicamente estabelecido, novos conhecimentos e novas fronteiras a serem conquistadas. 
Em segundo lugar, em sentido mais estrito, a educação reflete a imediatez histórica de uma determinada forma de organização social. Em diferentes momentos históricos e em diferentes formas societárias, a educação se apresenta ora como elemento contestador no interior das relações sociais, ora como elemento reforçador dessas mesmas relações sociais. Inclusive a maneira como a educação é entendida também vai se transformando conforme mudam as condições e interesses sociais que sobre ela incidem. A forma como a educação se apresenta e as funções específicas às quais responde expressam muito fielmente a própria organização social, neste sentido é que a imediatez histórica pode ser identificada na educação.

Entendida no contexto sócio histórico das múltiplas determinações que compõem o homem, a educação é essencial para a manutenção, aperfeiçoamento e transformação das civilizações ao longo da história humana. Em diferentes momentos, a transmissão do acúmulo de conhecimentos por uma geração à outra assumiu diferentes formas, contudo, sua função permaneceu sempre a mesma, qual seja, formar adultos capazes de manter ou transformar as condições históricas da humanidade. -Esta relação entre o progresso histórico e o progresso da educação é tão estreita que se pode sem risco de errar julgar o nível geral do desenvolvimento histórico da sociedade pelo nível de desenvolvimento do seu sistema educativo e inversamentell. (LEONTIEV, 1978, p. 267). Com isto, pode-se entender que o processo educativo não pode ser distanciado do desenvolvimento histórico. Por isso, à educação não pode ser atribuído o papel de redenção social, ou o caráter emancipatório se ela estiver desvinculada da totalidade das relações sociais que ela representa e expressa.

Educação, então, está indissoluvelmente ligada ao desenvolvimento sócio histórico. Atribuir a ela papel de emancipadora em uma sociedade que não emancipa, ou, que emancipa apenas parcialmente, politicamente, é entendê-la como se estivesse separada daquilo que lhe dá significado. Uma característica marcante nos projetos educacionais ditos emancipatórios na atualidade é a pretensão de garantir que o aluno será capaz de conduzirse pelo mundo de modo autônomo, crítico e consciente. A ênfase é na sua capacidade em aprender a aprender, a idéia de emancipação aparece como reforço da esfera pessoal. Munido de suas vontades, aspirações e sonhos, o aluno seria capaz de construir em si o conhecimento, como protagonista de sua própria aprendizagem, construindo o saber 
necessário à transformação na mentalidade, mudando a realidade imediata, tendo consigo a mediação do professor.

Ao procurar oferecer ao aluno conhecimentos que sejam úteis no presente, desconsiderando o feixe de relações sócio históricas que dão corpo a tais conhecimentos, ignorando as lutas, as conquistas, os erros e os acertos da gerações anteriores, as propostas ditas —emancipatóriasll prometem um protagonismo tido como manifestação de uma educação diferente do que é chamado de -tradicionalll: o planejamento, a estruturação curricular, o método, as disciplinas historicamente constituídas e o conhecimento científico acerca do mundo.

A atenção maior focada no processo de aprender, e não no produto da aprendizagem asseguraria ao estudante a possibilidade de se tornar sujeito de sua própria história e, por si só, este processo enriqueceria as possibilidades renovadas de uma sociedade em transformação. A educação é apresentada como redentora da sociedade. Na perspectiva, ainda, das propostas ditas -emancipatóriasll em educação, a ênfase está atrelada ao dístico do progresso e da capacidade do aluno de aprender a aprender, gerando transformação social. O progresso viria partejado pela iniciativa individual do aluno protagonista, aprendiz sujeito de sua própria aprendizagem, capaz de, a partir de suas impressões pessoais, transformar toda uma realidade histórica.

Isto fica mais claro quando se considera um dos pilares das propostas emancipatórias: 0 aprender a aprender requer que o aluno se coloque como protagonista do processo de aprendizagem. O estudante determina o ritmo, o tema, o enfoque, o método, enfim, é ele quem viabiliza aquilo que deseja aprender. Há uma aparente liberdade de escolha, porém, há muito mais elementos de dependência que de emancipação. O protagonismo não só não pode realizar-se, como não se mostra mais emancipador. Protagonista falso no presente imediato do projeto de aprendizagem, a não emancipação torna o sujeito peão das estratégias e metodologias do trabalho flexível a longo prazo. (BENSAID, 2000).

A emancipação, assim, é entendida como sendo proveniente de uma vontade, independe da história real. Esta vontade fundamentaria uma ação em direção à emancipação dos homens. Atribuir à vontade ahistórica a realização de qualquer programa emancipatório é consagrá-lo como emancipação política, pois não atinge o que sustenta a alienação: a sociedade da propriedade privada dos meios de produção. 
Quando a educação —inovadorall anseia pela emancipação política sem aludir, ou lutar, pela emancipação humana, anseia por cidadania encarcerada na dinâmica das contradições da própria forma societária que sustenta a alienação.

A emancipação humana só pode começar com a anulação, a destruição e a superação da propriedade privada dos meios de produção. Isto as -tendências pedagógicas emancipatórias\|l desconsideram por completo. Não supõem a superação da luta de classes ou da propriedade privada burguesa, ao contrário, as reforça, aprofundando as diferenças sociais decorrentes da propriedade privada burguesa e da alienação do trabalho. A educação não pode ser emancipatória numa perspectiva moral, porque neste caso não há ruptura com a ordem que alimenta a alienação. Clamar pela educação emancipatória, sem superar as forças produtivas que nutrem a alienação é proferir discurso moral. Não emancipa, mas aprisiona na servidão do trabalho assalariado e na lógica da propriedade privada. A desejada emancipação pela educação não se realiza porque pretende emancipar dentro da mesma estrutura que aprisiona.

\section{CONSIDERAÇÕES FINAIS}

Embora seja uma instituição fundamental à superação da alienação e à conquista da emancipação humana, a educação não é suficiente para redimir sociedade das mazelas constituídas historicamente. Se, por um lado, a educação é capaz de identificar as limitações e contradições sociais do capitalismo, por outro lado, opera em favor da manutenção das instituições existentes quando sugere a emancipação na liberdade de escolha e no aprender a aprender. A limitação está no fato de que as propostas ditas -emancipatórias\|l concebem a educação como redenção social, mas partem da mesma base material cujas manifestações procura denunciar, criticar e negar. Ao conceber a alienação do homem a partir do ponto de vista do capital, a educação não tem condições de propor sua superação a não ser no quadro dos postulados morais mais gerais e na conformação reformista da sociedade capitalista, procurando melhorar ou humanizar a sociedade existente, sem o entendimento de que são as próprias contradições desta sociedade que produzem as mazelas que se deseja eliminar.

Assim, além da reprodução, numa escala ampliada, das múltiplas habilidades sem as quais a atividade produtiva não poderia ser levada a cabo, o complexo sistema educacional da sociedade é também responsável pela produção e reprodução da 
estrutura de valores no interior da qual os indivíduos definem seus próprios objetivos e fins específicos. As relações sociais de produção reificadas sob o capitalismo não se perpetuam automaticamente. Elas só o fazem porque os indivíduos particulares internalizam as pressões externas: eles adotam as perspectivas gerais da sociedade de mercadorias como os limites inquestionáveis de suas próprias aspirações. É com isso que os indivíduos —contribuem para manter uma certa concepção do mundoll e para a manutenção de uma forma específica de intercâmbio social, que corresponde àquela concepção do mundo. (MÉSZÁROS, 2007, p. 263).

Assim, a superação da alienação e a conquista da emancipação humana é também uma tarefa educacional, porém, apenas quando esta tarefa assume o caráter de ruptura profunda. Nos limites da modificação política ou do clamor moral pela melhoria das atuais condições de vida, sem a profunda transformação social, a educação mantém um clamor moral, alimentando uma universalidade fictícia, contribuindo para a manutenção de uma concepção de mundo que interioriza nos indivíduos os valores da sociedade das mercadorias, da sociedade capitalista, em cujo seio a emancipação é parcial. Fica ao homem impedido de realizar suas potencialidades através da educação que, por sua vez, expressa e reforça a parcialidade.

Por outro lado, se tomada a partir do ponto de vista da totalidade, a educação é atividade social que produz o ser humano capaz de inventar potencialidades e fruir delas socialmente. Somente quando entendida como parcialidade no interior da totalidade das relações sociais e históricas, é que a educação pode assumir seu papel de emancipadora. A mesma ordem social que gesta a alienação traz em si os elementos da superação da alienação e, pela formação humana efetivamente comprometida com a transmissão histórica das contradições que elevam o homem à condição de produtor e produto de sua própria vida, é que se pode considerar seriamente a possibilidade de uma sociedade melhor do que a existente.

\section{REFERÊNCIAS BIBLIOGRÁFICAS}

BENSAID, Daniel. Trabalho e Emancipação. IN: LOWY, Michael \& BENSAID, Daniel. Marxismo, Modernidade e Utopia. São Paulo: Xamã, 2000.

DA MATA, Vilson Aparecido. Homero e Hesíodo: a construção da consciência sobre o homem e seu corpo na Grécia Arcaica. Maringá: Universidade Estadual de Maringá. 
Dissertação de Mestrado, 2000.

JACOBY, Russell. O Fim da Utopia: política e cultura na era da apatia. Rio de Janeiro, São Paulo: Editora Record, 2001.

LEONTIEV, Alexis. O Desenvolvimento do Psiquismo. Lisboa: Livros Horizonte, 1978.

MARX, Karl. On de Jewish Question. IN: MARX, Karl e ENGELS, Friedrich. Collected Works. New York: International Publishers, 2005 (Volume 3); p. 146 - 174.

MÉSZÁROS, István. A Teoria da Alienação em Marx. São Paulo: Boitempo Editorial, 2007.

MORE, Thomas. A Utopia. São Paulo: Ed. Nova Cultural. 2004. (Col. Os Pensadores) VÁZQUEZ, Adolfo Sánchez. Entre a Realidade e a Utopia: ensaios sobre política, moral e socialismo. Rio de Janeiro; Civilização Brasileira, 2001.

* Graduado em Educação Física pela Universidade Estadual de Maringá (1991) e mestre em Educação pela Universidade Estadual de Maringá (2000). Atualmente é professor da Universidade Federal do Paraná (UFPR).

1

DA MATA, Vilson Aparecido. Homero e Hesíodo: a construção da consciência sobre o homem e seu corpo na Grécia Arcaica. Maringá: Universidade Estadual de Maringá. Dissertação de Mestrado, 2000, p. 05.

2 Neste texto, utilizar-se-á utopia, em minúsculo, quando estiver se referindo a utopia de forma geral e Utopia, em maiúsculo, como nome próprio, quando a referência é ao livro de More, ou ao local onde localiza sua sociedade ideal, a ilha de Utopia.

3

Além de Thomas More, outros escritores clássicos com obras importantes e que se colocam no campo da utopia, são: Francis Bacon, autor de Nova Atlântida (1627) e Tommaso Campanella, que escreveu A Cidade do Sol (1602).

4

Para o presente artigo, o texto a ser utilizado é - Sobre a Questão Judaicall, de Karl Marx, a partir da excelente tradução do alemão para o inglês da International Publishers. Será utilizado o volume 3 de Collected Works, trabalho meticuloso de tradução realizado por Grã-Bretanha, EUA e União Soviética e ainda em andamento, de compilação e tradução das obras de Marx e Engels. 
ENVIADO EM: 01.12. 2011

APROVADO EM: 20.12. 2011 